\title{
Using content analysis to inform health communication efforts on social media: Is popularity the goal?
}

\author{
Wen-Ying Sylvia Chou \\ Health Communication and Informatics Research Branch, Division of Cancer Control and Prevention, National Cancer Institute, Rockville, MD, \\ USA \\ Correspondence to: Wen-Ying Sylvia Chou, PhD, MPH. Health Communication and Informatics Research Branch, National Cancer Institute, 9609 \\ Medical Center Drive, 3E614, Bethesda, MD 20892, USA. Email: chouws@mail.nih.gov. \\ Comment on: Oviatt JR, Reich SM. Pregnancy posting: exploring characteristics of social media posts around pregnancy and user engagement. \\ Mhealth 2019;5:46.
}

Received: 02 April 2020; Accepted: 15 April 2020; Published: 20 July 2021.

doi: $10.21037 /$ mhealth-2020-1

View this article at: http://dx.doi.org/10.21037/mhealth-2020-1

The article by Oviatt and Reich (1) presents a thoughtful and thorough content analysis of pregnancy-related groups on Facebook and Instagram, with the goals of classifying the purpose of the posts, understanding user engagement, and identifying characteristics of popular $v s$. unpopular posts. Examining the dynamics and characteristics of content posted to online communities focused on particular health topics (in this case, women's concerns and interests related to pregnancy) is very timely given the growing influence of such forums. The analysis also speaks to the increasingly central role that social media plays as a health information source as well as a means of fostering connection between individuals with similar health concerns or experiences.

One notable finding from the analysis relates to the identification of characteristics that seem to drive engagement with content on these platforms. The authors suggest that posts emphasizing a shared experience (i.e., making pregnancy "relatable") or offering emotional support/validation to pregnant women received more user engagement. These observations are in line with findings from previous social media studies indicating that engagement in social networking communities is driven by the desire to relate and find common ground, reaffirm certain shared identities or experiences, and validate feelings, attitudes, and perceptions (2-4). One caveat to note related to this observation is the risk of these social media communities amplifying certain aligned/relatable sentiments; social media may reaffirm our confirmation bias and reinforce information silos, thereby discouraging different perspectives such as "unpopular" posts.

Oviatt and Reich also found other post characteristics that were associated with higher levels of engagement included the use of "real" photos (as opposed to highly produced commercial ones) and the presence of humor. These elements could also help increase the feeling of community and authentic participation among users of these social media accounts-for example, because women can recognize themselves in the images of "real" women, and can feel "in" on the jokes that only women who have experienced pregnancy would understand.

The findings from this study regarding individual post characteristics that generate user engagement could be valuable to public health practitioners seeking tips for content development. In particular, one of the key takeaways from this paper serves as a reminder to public health practitioners that creating a sense of community and belonging could be the key to successful and engaging social media efforts.

However, an important caution should be offered about applying the findings of this paper in practice. The analysis is limited by the fact that "engagement" is measured solely by standard social media metrics including likes, comments, shares; these measures are not necessarily a useful proxy for the informational or socio-emotional "needs" of users. The findings from this study can help practitioners who are looking to increase engagement with their social media content, but they don't necessarily point to how practitioners can make their interventions more "effective" either in terms of successfully changing this population's knowledge, 
attitudes, or behaviors, or in terms of successfully identifying and addressing this population's needs. Just because informational posts were found to be less "popular" (as measured by fewer likes) does not mean that these kinds of posts are unneeded, necessarily disliked by users, or contained information that individuals perceived helpful or even acted upon. Engagement may not always be a reliable or consistent reflection of how people perceive a post, and social norms about the type of content that gets a response on social media may contribute to differences in engagement between posts. For example, people may read informational posts and find them useful, but not feel that they need to engage with the post in any other way, whereas they may feel that it is important to endorse or share posts that empower or validate pregnant women as a way to convey solidarity or express their identity. Research that looks at user reactions to social media content more comprehensively (e.g., through interviews or surveys of users) are needed to offer a more nuanced understanding of user engagement with social media content and how engagement relates to actual perceptions of posts as well as the impact of viewing the posts.

\section{Acknowledgments}

The author would like to thank Anna Gaysynsky and Robin Vanderpool for their thoughtful feedback on a draft of this commentary. The opinions expressed by the author are her own and should not be interpreted as representing the official viewpoint of the U.S. Department of Health and Human Services, the National Institutes of Health or the National Cancer Institute.

Funding: None.

\section{Footnote}

Provenance and Peer Review: This article was commissioned by the editorial office, mHealth. The article did not undergo external peer review.

Conflicts of Interest: The author has completed the ICMJE uniform disclosure form (available at http://dx.doi. org/10.21037/mhealth-2020-1). The author has no conflicts of interest to declare.

Ethical Statement: The author is accountable for all aspects of the work in ensuring that questions related to the accuracy or integrity of any part of the work are appropriately investigated and resolved.

Open Access Statement: This is an Open Access article distributed in accordance with the Creative Commons Attribution-NonCommercial-NoDerivs 4.0 International License (CC BY-NC-ND 4.0), which permits the noncommercial replication and distribution of the article with the strict proviso that no changes or edits are made and the original work is properly cited (including links to both the formal publication through the relevant DOI and the license). See: https://creativecommons.org/licenses/by-nc-nd/4.0/.

\section{References}

1. Oviatt JR, Reich SM. Pregnancy posting: exploring characteristics of social media posts around pregnancy and user engagement. Mhealth 2019;5:46.

2. Moreno MA, Kota R, Schoohs S, et al. The Facebook influence model: a concept mapping approach. Cyberpsychol Behav Soc Netw 2013;16:504-11.

3. Chou WY, Prestin A, Lyons C, et al. Web 2.0 for health promotion: reviewing the current evidence. Am J Public Health 2013;103:e9-18.

4. Pagoto S, Waring ME, Xu R. A Call for a Public Health Agenda for Social Media Research. J Med Internet Res 2019;21:e16661. doi: 10.21037/mhealth-2020-1

Cite this article as: Chou WYS. Using content analysis to inform health communication efforts on social media: Is popularity the goal? mHealth 2021;7:40. 